\title{
Reversal of Acute Myelogenous Leukemia in Humanized SCID Mice Using a Novel Adoptive Transfer Approach
}

\author{
Alessandra Cesano, Sophie Visonneau, Livia Cioé, Steven C. Clark, * Giovanni Rovera, and Daniela Santoli \\ The Wistar Institute of Anatomy and Biology, Philadelphia, Pennsylvania 19104; and *Genetics Institute, \\ Cambridge, Massachusetts 02140
}

\begin{abstract}
Advanced human malignancies cannot be permanently cured by adoptive transfer of autologous lymphokine-activated killer (LAK) cells. Moreover, administration of high doses of IL-2 to maintain LAK activity in vivo is associated with severe toxicity. In this study, we tested the anti-tumor efficacy of a uniquely potent MHC non-restricted human killer $T$ cell clone (TALL-104) in humanized severe combined immunodeficient (SCID) mice bearing acute myelogenous leukemia (AML). We show that, in appropriate experimental conditions, TALL-104 cells could effectively reverse the aggressive growth of the myelomonocytic leukemia cell line U937 in SCID mouse tissues, leading to complete abrogation of AML. A single transfer of TALL-104 cells at the time of tumor challenge in combination with recombinant human (rh) IL-12 (1 $\mu \mathrm{g} / \mathrm{d})$ prolonged significantly the life of the mice. However, eradication of leukemia, as monitored both clinically and by PCR, was achieved by repeated injection of the effectors at close intervals. Complete cure was obtained also upon transfer of lethally irradiated (non-proliferating) TALL-104 cells together with low doses of rh IL-2 (100 U/d). Most notably, of the mice that received multiple transfers of TALL-104 cells without cytokines in an advanced disease stage, $\mathbf{5 0 \%}$ were clinically cured, and $\mathbf{5 0 \%}$ survived significantly longer. The potential of TALL-104 cells as an effective and safe leukemia purging agent is discussed. (J. Clin. Invest. 1994. 94:1076-1084.) Key words: irradiated killers - adoptive transfer therapy - marrow purging • minimal residual disease • interleukin-12
\end{abstract}

\section{Introduction}

The achievement of temporary remission in a variety of human cancers (1-3) clearly points to the potential of lymphokineactivated killer (LAK) ${ }^{1}$ cell therapy. However, LAK cell therAddress correspondence to D. Santoli, Ph.D., The Wistar Institute, 3601
Spruce Street, Philadelphia, PA 19104.
Received for publication 14 December 1993 and in revised form 31
May 1994.

1. Abbreviations used in this paper: AML, acute myelogenous leukemia; ABMT, autologous bone marrow transplantation; BM, bone marrow; CsA, Cyclosporin A; E/T ratio, effector/target ratio; i.p., intraperitoneal; LAK, lymphokine-activated killer; MRD, minimal residual disease; PB, peripheral blood; rh, recombinant human; SCID, severe combined immunodeficient.

J. Clin. Invest.

(c) The American Society for Clinical Investigation, Inc.

0021-9738/94/09/1076/09 \$2.00

Volume 94, September 1994, 1076-1084 apy has had little success against established metastatic disease (2). Two major problems affect the efficiency of adoptively transferred LAK cells: one is the inadequate tumoricidal activity of these MHC nonrestricted polyclonal killer cells; the second is the unavailability of sufficient numbers of activated effectors that retain both cytotoxic and tumor-targeting capabilities. The high doses of recombinant human ( $\mathrm{rh}$ ) IL-2 administered to the patients to circumvent these limitations have been associated with severe side effects $(2,4-6)$. Several alternate approaches have been proposed to improve cancer therapy, including the use of antigen-specific tumor-infiltrating cytotoxic lymphocytes $(7,8)$ or of LAK cells linked with antibodies to tumor cell surface antigens $(9,10)$, and genetic engineering of tumor cells with cytokine genes (such as IL-2, TNF, IFN- $\gamma$, IL-4, IL-6, and IL-7), to promote enhanced anti-tumor immunity (11-15).

Within hematologic malignancies, therapy with LAK cells and IL-2 has induced some clinical responses in patients with advanced malignant lymphoma or acute myelogenous leukemia (AML) (16). It is postulated that administration of LAK cells with IL-2 might prevent or delay relapses if used as consolidative immunotherapy against the minimal residual disease (MRD) which exists after autologous bone marrow transplantation (ABMT). Although IL-2-responsive LAK precursor cells are in the circulation as early as $3 \mathrm{wk}$ after ABMT, full LAK activity is recovered only $70-80 \mathrm{~d}$ after the transplant. The feasibility of generating and administering autologous LAK cells and IL-2 after ABMT in patients with high risk of relapse is now under investigation (16). However, this therapeutic modality might have practical limitations in many patients with AML or acute lymphoblastic leukemia due to the scarcity of cytotoxic cells in their blood and to the often rapid disease progression.

We have developed a new experimental approach to adoptive immunotherapy that overcomes the inadequacy of autologous LAK cells and the severe side effects of rh IL-2 in vivo. This approach uses a lethally irradiated clonal human $\mathrm{T}$ cell line (TALL-104), which is endowed with potent MHC nonrestricted cytotoxic activity directed exclusively against tumor cells (1719). The TALL-104 cell line, originally derived from an infant with acute T-lymphoblastic leukemia (17), has phenotypic markers typical of cytotoxic $\mathrm{T}$ cells $\left(\mathrm{CD} 2^{+}, \mathrm{CD} 3 / \mathrm{TCR} \alpha \beta^{+}\right.$, $\mathrm{CD}^{-} / \mathrm{CD}^{+}, \mathrm{CD}^{+}, \mathrm{CD}^{+} 6^{+}, \mathrm{CD}^{-} 6^{-}$) and is maintained in continuous culture in the presence of rh IL-2. Its cytotoxicity can be supported independently by IL- 2 or IL-12 and the two cytokines trigger this function in an additive fashion (20). The ability of this cell line to engraft severe combined immunodeficient (SCID) mice (21) offered to us the opportunity to investigate its anti-tumor effects in an in vivo setting of human malignancies that can be implanted in these animals, including lymphoid and myeloid leukemias (21-23). The SCID/U937 model was chosen in the present study because this human myelomonocytic leukemia cell line $(a)$ is highly sensitive to LAK cell lysis, and $(b)$ grows aggressively in SCID mice induc- 
ing fatal leukemia in a short time period (22). Our findings demonstrate that in appropriate experimental conditions, TALL104 cells can reverse the aggressive growth of U937 cells in SCID mouse tissues, leading to complete abrogation of AML. Moreover, multiple transfers of lethally irradiated TALL-104 cells co-injected with rh IL-2 at the time of tumor challenge completely eradicated the presence of U937 cells in the murine host. These findings suggest the possible use of cytokine-activated, nonproliferating, allogeneic effectors in adoptive transfer therapy.

\section{Methods}

Cell lines. The following human tumor cell lines were cultured at $37^{\circ} \mathrm{C}$ in $5 \% \mathrm{CO}_{2}$ in RPMI 1640 medium supplemented with $10 \%$ heat-inactivated FBS, glutamine, and antibiotics: U937 (myelomonocytic leukemia ), Raji ( B cell lymphoma), U-87MG ( glioblastoma ), 2774 ( ovarian carcinoma), Hs568T (breast carcinoma), 5673 (bladder carcinoma). A549 (lung carcinoma), and CHP-100 (neuroblastoma). All cell lines were free of mycoplasma contamination upon repeated testing. TALL104 cells were maintained in Iscove's modified Dulbecco's medium supplemented with $10 \%$ FBS and rh IL-2 $(100 \mathrm{U} / \mathrm{ml})\left(\mathrm{sp}\right.$ act $1 \times 10^{7}$ $\mathrm{U} / \mathrm{mg}$ ), a generous gift from Dr. Maurice Gately (Hoffman-La Roche. Nutley, NJ).

Tagging of U937 cells with a neomycin-resistance gene. The N2A double copy retroviral vector. containing the neomycin-resistance gene and the human IL-2 cDNA driven by the thymidine kinase promoter (24, 25) was obtained from Drs. E. Gilboa and Gansbacher (Memorial Sloan-Kettering Cancer Center. New York. NY) and used to infect U937 cells by lipofection according to published methods (26). G-418 (genetycin. $1 \mathrm{mg} / \mathrm{ml}$ ) -resistant U937 clones were subcloned by limiting dilution.

Mice. CB17 SCID mice, originally obtained from Dr. M. Bosma (Fox Chase Cancer Center, Philadelphia, PA), were bred and maintained in The Wistar Institute's animal facility. 6-wk-old IgM nonproducer SCID mice were immunosuppressed by intraperitoneal (i.p.) injection of etoposide (VP-16, $30 \mathrm{mg} / \mathrm{kg}$ ), $4 \mathrm{~d}$ before implantation of U937 cells. Organs were minced through metal grids followed by FicollHypaque gradients to remove dead cells and erythrocytes (21-23). Bone marrow ( $\mathrm{BM})$ samples from the femoral bones and peripheral blood ( $\mathrm{PB}$ ) drawn from the eye were stained with May-Grünwald Giemsa (21-23)

Cytotoxicity assays. IL-2-activated TALL-104 cells were tested at four different concentrations in $4-\mathrm{h}{ }^{5} \mathrm{Cr}$-release assays against a fixed number $\left(10^{4} /\right.$ well ) of human tumor cell lines (see above) or FicollHypaque separated human BM cells. Specific ${ }^{51} \mathrm{Cr}$-release was calculated from the mean of three replicates and the results were expressed as $40 \%$ lytic units $/ 10^{\circ}$ effectors, as described (17-20).

Detection of residual U9.37 cells by PCR. PCR amplification of the neomycin-resistance gene present in U937 cells (see above) was done using two neomycin-specific primers which were synthesized in the DNA synthesis facility of the University of Pennsylvania ( Philadelphia. PA). The sequence amplified by these primers is of $501 \mathrm{bp}$. A ${ }^{32} \mathrm{P}$ labeled oligonucleotide probe recognizing 20 nucleotides in the middle of the amplified sequence was used for Southern blot hybridization to demonstrate the specificity of the PCR products (22). DNAs were visualized with ethidium bromide after electrophoresis in $2 \%$ agarose gels, $1 \times$ TAE buffer. Hybridization was carried out overnight at $50^{\circ} \mathrm{C}$ in $5 \times$ SSC. $1 \%$ SDS at room temperature for $30 \mathrm{~min}$, and $2 \times$ SSC, $1 \%$ SDS for $30 \mathrm{~min}$ at $56^{\circ} \mathrm{C}\left(4^{\circ} \mathrm{C}\right.$ less than the melting point of the oligo probe). The sensitivity of our PCR method using neomycin-specific primers allows us to detect one positive cell out of $2 \times 10^{5}$ cells.

PCR identification of human cells in the murine host. The presence of human cells ( either effectors or targets) in SCID mouse tissues was evaluated by PCR analysis using two primers specific for human ALUDNA sequences (27). An oligonucleotide probe recognizing 20 nucleotides in the middle of the amplified sequence ( $221 \mathrm{bp}$ ) was used to

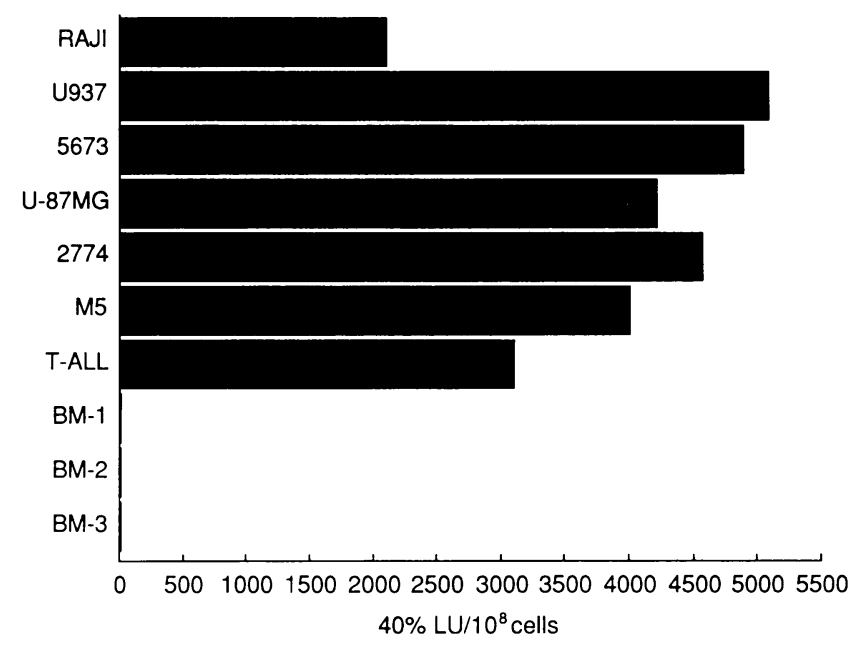

Figure 1. Selective killing of tumor targets by TALL-104 cells. ${ }^{51} \mathrm{Cr}$ labeled tumor targets and normal BM (BMI-BM3) listed in the ordinate $\left(10^{4} /\right.$ well $)$ were tested for susceptibility to lysis by TALL- 104 cells at four different concentrations. The results of the 4-h cytotoxic assay were expressed as $40 \%$ lytic units $/ 10^{x}$ effectors.

demonstrate the specificity of the PCR products by Southern blot hybridization (22).

\section{Results}

Tumoricidal activity of TALL-104 cells in vitro. Short-term effects of $\gamma$-irradiation. TALL- 104 cells display potent cytotoxic activity directed exclusively against tumor targets and do not lyse normal cells. Fig. 1 shows a representative 4 -h ${ }^{51} \mathrm{Cr}$-release assay in which cultured leukemic cell lines (Raji, U937), cell lines originated from solid tumors ( the bladder carcinoma 5673, the glioblastoma multiform U-87 MG, and the ovarian carcinoma 2774), and uncultured cells freshly isolated from leukemic BM samples (an AML/FAB-M5 and a T-ALL), were efficiently lysed by TALL-104 cells, whereas the BM from three healthy donors (BM1, BM2, and BM3) were not affected at all. As detailed in a separate manuscript (Cesano, A., S. Visonneau, L. Cioé, S. C. Clark, and D. Santoli, manuscript submitted for publication), $\gamma$-irradiation (4.000 rads, provided by a cesium source) blocks TALL-104 cell proliferation completely ( ${ }^{3} \mathrm{H}-\mathrm{TdR}$ incorporation is totally inhibited within $4 \mathrm{~h}$ ) without significantly altering their killer function. Fig. 2 shows an experiment in which IL-2-activated TALL-104 cells were $\gamma$ irradiated and immediately tested for cytotoxicity in a 4-h ${ }^{51} \mathrm{Cr}$-release assay: all types of human tumor targets tested (U937, U-87 MG, 2774, the lung carcinoma A549, breast cancer Hs568T. and neuroblastoma CHP-100) were killed as efficiently by the irradiated killers as by the nonirradiated counterpart at all effector/target $(\mathrm{E} / \mathrm{T})$ ratios tested.

Long-term effects of $\gamma$-irradiation on TALL-104 cell killing in response to $r h I L-2$ and $r h I L-12$. To compare the long-term cytotoxic responses of irradiated and nonirradiated TALL- 104 cells to the same doses of IL-2 and IL-12, the U937 clone tagged with the neomycin-resistance gene was used as target, and PCR analysis using neomycin-specific primers was performed after a 5-d incubation. Fig. 3 shows that when nonirradiated TALL- 104 cells were used, activation with rh IL-2 ( 100 $\mathrm{U} / \mathrm{ml})$ or $\mathrm{rh} \mathrm{IL}-12(10 \mathrm{ng} / \mathrm{ml})(\mathrm{CHO}$ cell derived, sp act 5.2 $\times 10^{6} \mathrm{U} / \mathrm{mg}$ ) reduced the $\mathrm{E} / \mathrm{T}$ ratios necessary to eliminate 
U937
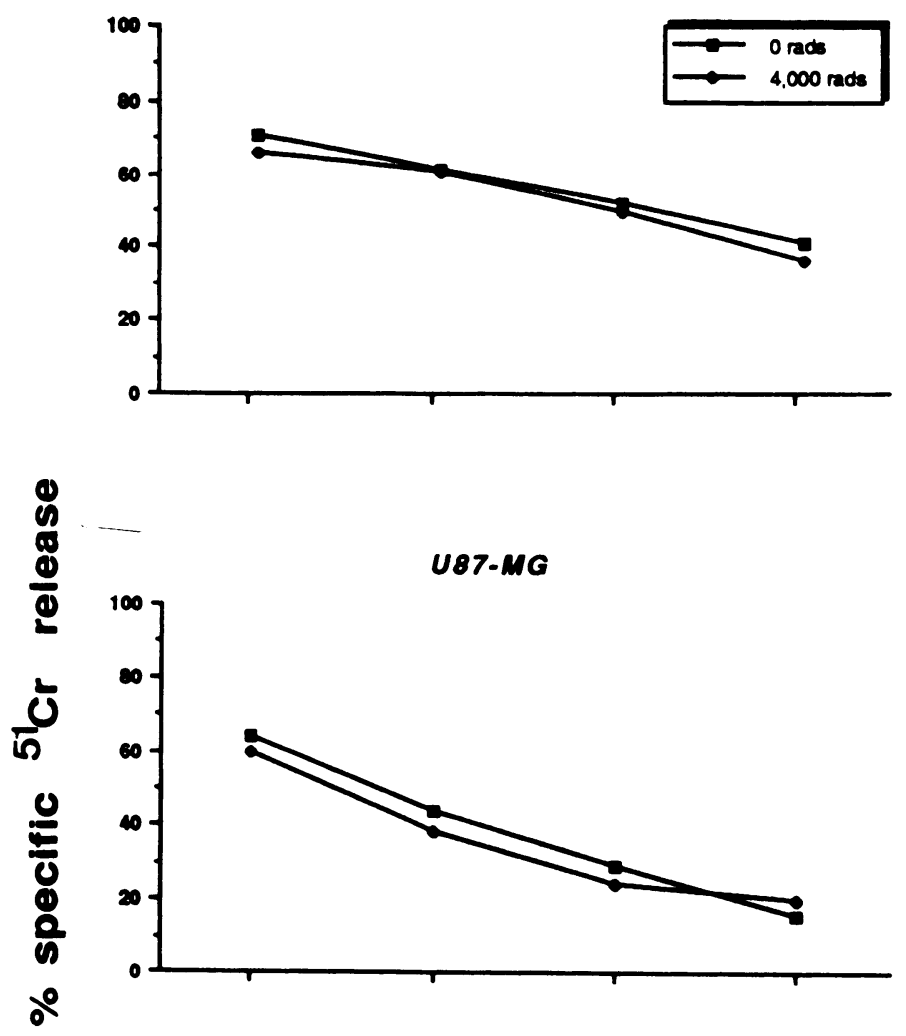

Hs568T

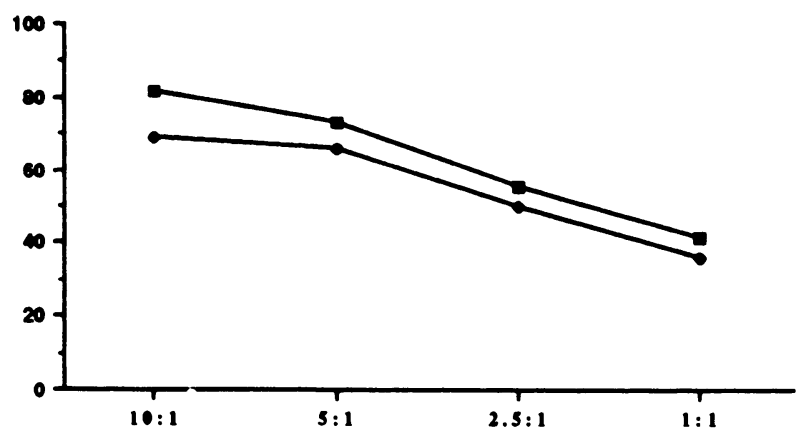

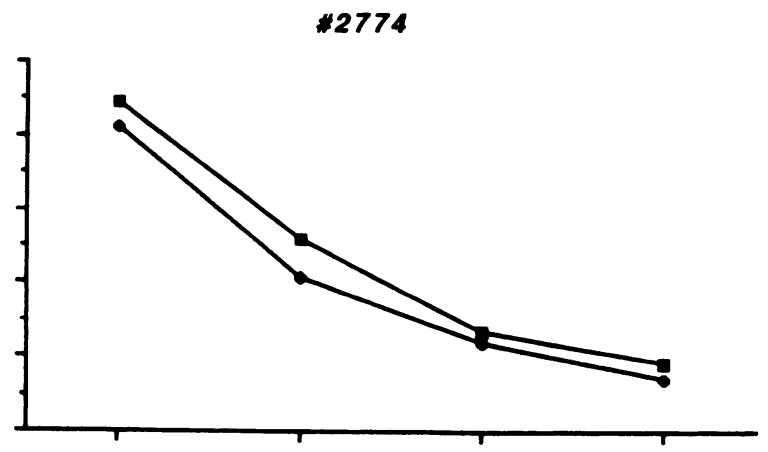

A549

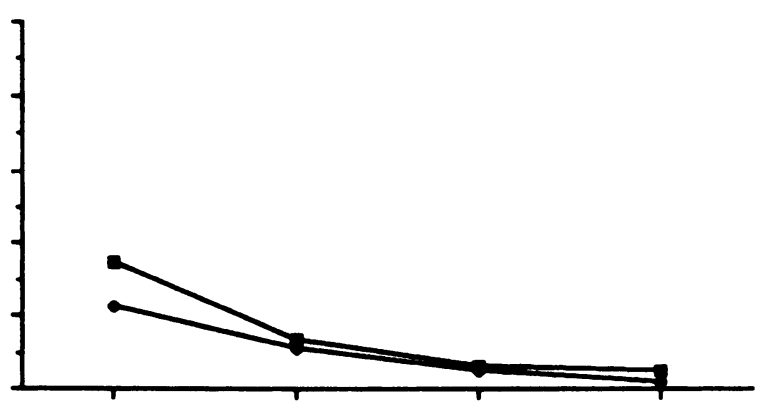

CHP. 100

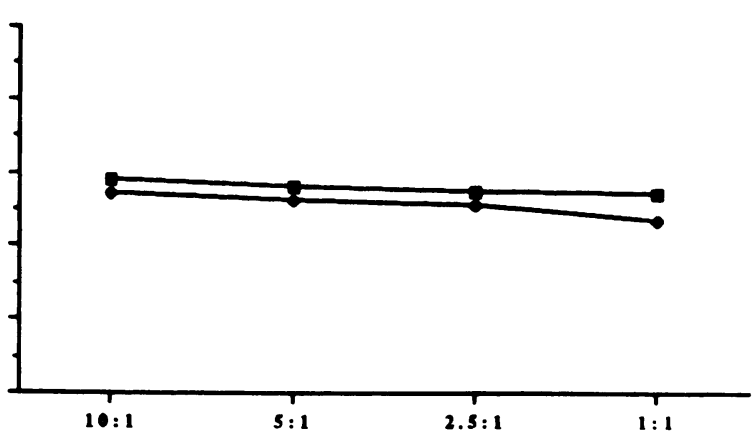

\section{E:T ratio}

Figure 2. Cytotoxic efficiency of $\gamma$-irradiated TALL-104 cells as compared to the nonirradiated effectors. TALL-104 cells activated with IL-2 were $\gamma$ irradiated (4,000 rads) and immediately tested for killer activity in a 4-h assay against ${ }^{51} \mathrm{Cr}$-labeled tumor targets at the indicated $\mathrm{E} / \mathrm{T}$ ratios.

$100 \%$ of the target cells from $1: 1$ to $0.1: 1$ and $0.5: 1$, respectively. When irradiated TALL-104 cells were used, the IL-2 responses in terms of killing efficiency were slightly reduced (U937 residual cells were detected at the $\mathrm{E} / \mathrm{T}$ ratio of $0.25: 1$ ) but no responses to IL-12 were detected (Fig. 3 ). Thus, although the immediate cytotoxic efficiency of TALL-104 cells is not affected by $\gamma$ irradiation (Fig. 2), the long-term cytotoxic responses of these cells to the cytokines are lower (in the case of IL-2) or completely abolished (in the case of IL-12) (Fig. 3).

Differential ability of irradiated and nonirradiated TALL104 cells to persist in SCID mouse tissues. Upon i.p. en- graftment into SCID mice, TALL-104 cells are able to proliferate in the absence of exogenous administration of rh IL-2, and induce fatal acute leukemia within 70-80 d, without causing graft-versus-host reaction (21). Lethally irradiated TALL-104 cells are no longer leukemogenic in SCID mice, confirming the gradual loss of viability observed in vitro (data not shown). The biodistribution and length of survival of the irradiated cells in SCID mouse tissue were investigated by injecting $10^{7}$ TALL104 cells i.p. into the animals, and by performing PCR analysis with primers specific to human ALU-DNA sequences on various organs and at different intervals. Fig. 4 compares the kinetics of biodistribution of irradiated and nonirradiated TALL-104 


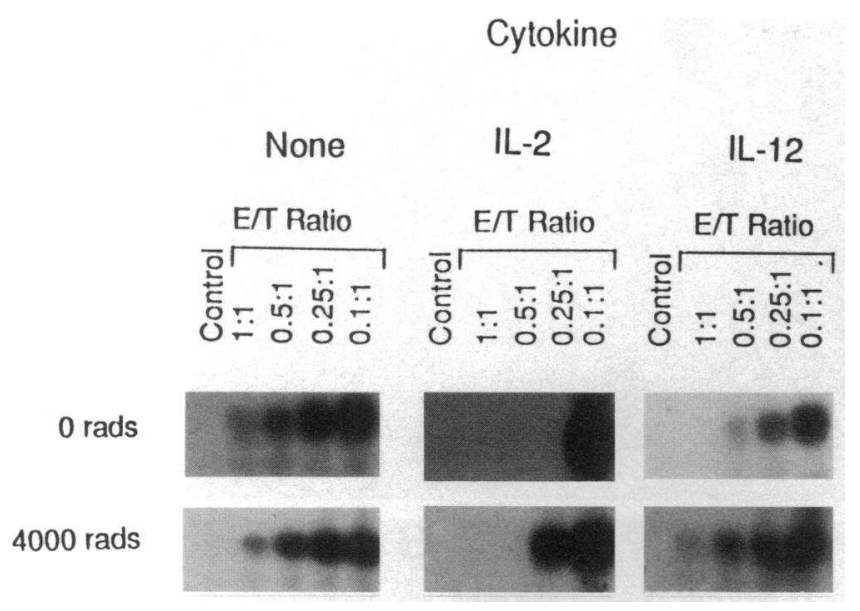

Figure 3. Detection of residual neomycin-tagged U937 cells after longterm incubation with irradiated and nonirradiated TALL-104 cells. The effectors $\left(1 \times 10^{6}\right)$ were incubated with the leukemic target at the indicated E/T ratios in 24-well plates, in the presence and absence of rh IL-2 $(100 \mathrm{U} / \mathrm{ml})$ or IL-12 $(10 \mathrm{ng} / \mathrm{ml})$. PCR analysis with neomycinspecific primers was done after $5 \mathrm{~d}$. Water was used as negative control.

cells in the PB, BM, spleen, lung, and liver in mice sacrificed on d 1, 3, and 5 after transfer: on d 1, both irradiated and nonirradiated TALL-104 cells were present in all of the organs and tissues examined; on $\mathrm{d} 3$, the irradiated cells were no longer detectable in the PB and liver; and by $\mathrm{d} 5$, they were detectable only in the BM. By contrast, as expected from previous work (21), the nonirradiated cells persisted in every organ (Fig. 4). These data show the ability of the irradiated cells to circulate and persist in SCID mouse tissues, at least for a few days after transfer.

Anti-leukemic effects of nonirradiated TALL-104 cells in humanized SCID mice. Mice were injected i.p. with various doses of U937 cells and checked daily for appearance of symptoms, consisting of hemorrhagic effusion in the testis, progressive enlargement of the abdomen, lethargy, and ruffled fur. The time of death in U937-injected mice was dependent on the number of tumor cells transferred: doses of $10^{7}$ cells killed the mice in $10 \mathrm{~d}$, and doses as low as $3 \times 10^{5}$ cells killed the mice within $50 \mathrm{~d}$ (Fig. 5). At autopsy, all mice presented large hemorrhagic ascites (3-4 ml), enlarged mesenteric lymph nodes, and extreme pallor of the ipocondriac organs due to

\section{NO RADS 4,000 RADS}

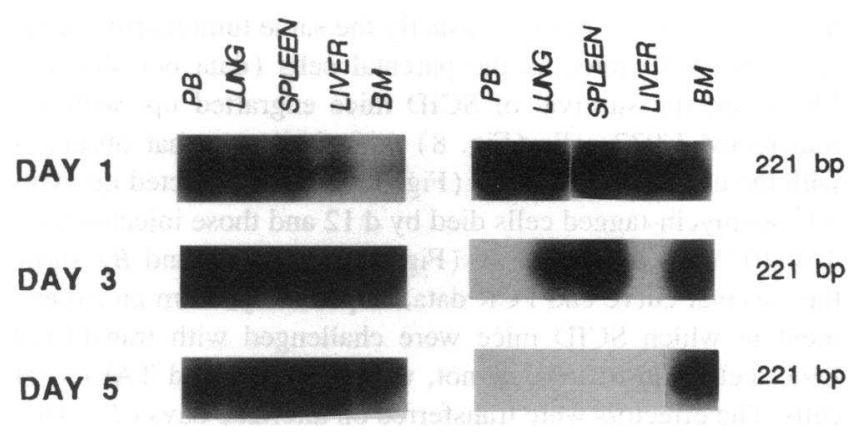

Figure 4. Comparative biodistribution of irradiated and nonirradiated TALL-104 cells in SCID mouse tissues. Detection of the i.p.-implanted TALL-104 cells was done by PCR using human ALU-DNA sequences.

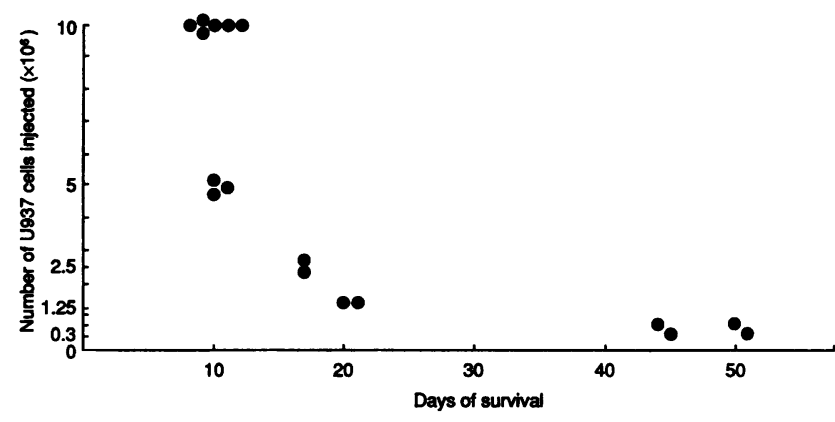

Figure 5. Survival of SCID mice engrafted i.p. with various doses of U937 cells. The doses of U937 cells are indicated in the ordinate. Each point represents an individual mouse.

severe anemia. U937 cells were always detectable in the ascites, PB, BM, and spleen of these mice at death. Fig. $6 a$ shows the heavy infiltration of the PB taken from a SCID mouse at death, $10 \mathrm{~d}$ after i.p. implantation of $10^{7} \mathrm{U} 937$ cells. The presence of PB infiltrates already on $\mathrm{d} 3$ (Fig. $6 \mathrm{~b}$ ) is a good indication of the aggressiveness of these leukemic cells in the murine host.

Animals receiving $10^{7}$ U937 cells were used to investigate the in vivo anti-tumor effects of TALL-104 cells; the cytotoxic activity of these effectors was optimized by priming the cells with $100 \mathrm{U} / \mathrm{ml}$ rh IL-2 for $18 \mathrm{~h}$ before in vivo transfer. Treatment was done at different times after injection of the AML target, and the survival of the mice was determined for a span of several months, as indicated in Fig. 7. Survivors, showing no symptoms after a 6-mo observation period, were sacrificed and the presence of human cells (both effectors and targets) in the BM was evaluated by PCR analysis using primers specific for human ALU-DNA sequences (27). The most remarkable finding in the experiments presented in Fig. 7 is that multiple transfers, at short intervals, of IL-2-activated TALL-104 cells cured $50 \%$ of the mice from an advanced stage of leukemia. In fact, of the mice injected with TALL-104 cells three times starting on $\mathrm{d} 3$, when U937 cells had already infiltrated the PB (Fig. $6 b$ ), two developed AML and died 3 mo later, and two remained clinically and morphologically free of disease for at least 6 mo (Fig. 7). PCR amplification of human ALU-DNA sequences provided molecular evidence for the persistence of residual cells in the BM of the survivors. Whether these cells represented TALL-104 effectors or U937 targets could not be determined in this set of experiments. Importantly, complete abrogation of AML, as monitored both clinically and by PCR analysis, was achieved by repeated injection of the effector cells on d 0,3 , and 6 (Fig. 7). TALL-104 cells were injected at the same time as U937 cells on d 0 (i.e., without any delay) but on the opposite flank. PCR amplification of human ALU-DNA sequences in the BM of these mice, electively sacrificed 6 mo from treatment, demonstrated that both types of leukemic populations, the myeloid target and the lymphoid effector, were eliminated from the mouse tissues. The possibility that, upon effective interaction with the U937 target, the TALL-104 cells might have become anergic and died is consistent with the notion that, upon lysis of sensitive targets, cytotoxic cells enter an anergic phase followed by apoptotic death (28). Another interesting observation from the experiments shown in Fig. 7 is that administration of low doses of rh IL-12 ( $1 \mu \mathrm{g} / \mathrm{d}$ for $7 \mathrm{~d})$ in conjunction with TALL-104 cells at the time of U937 cell challenge induced a significantly longer survival in the animals, as compared to 

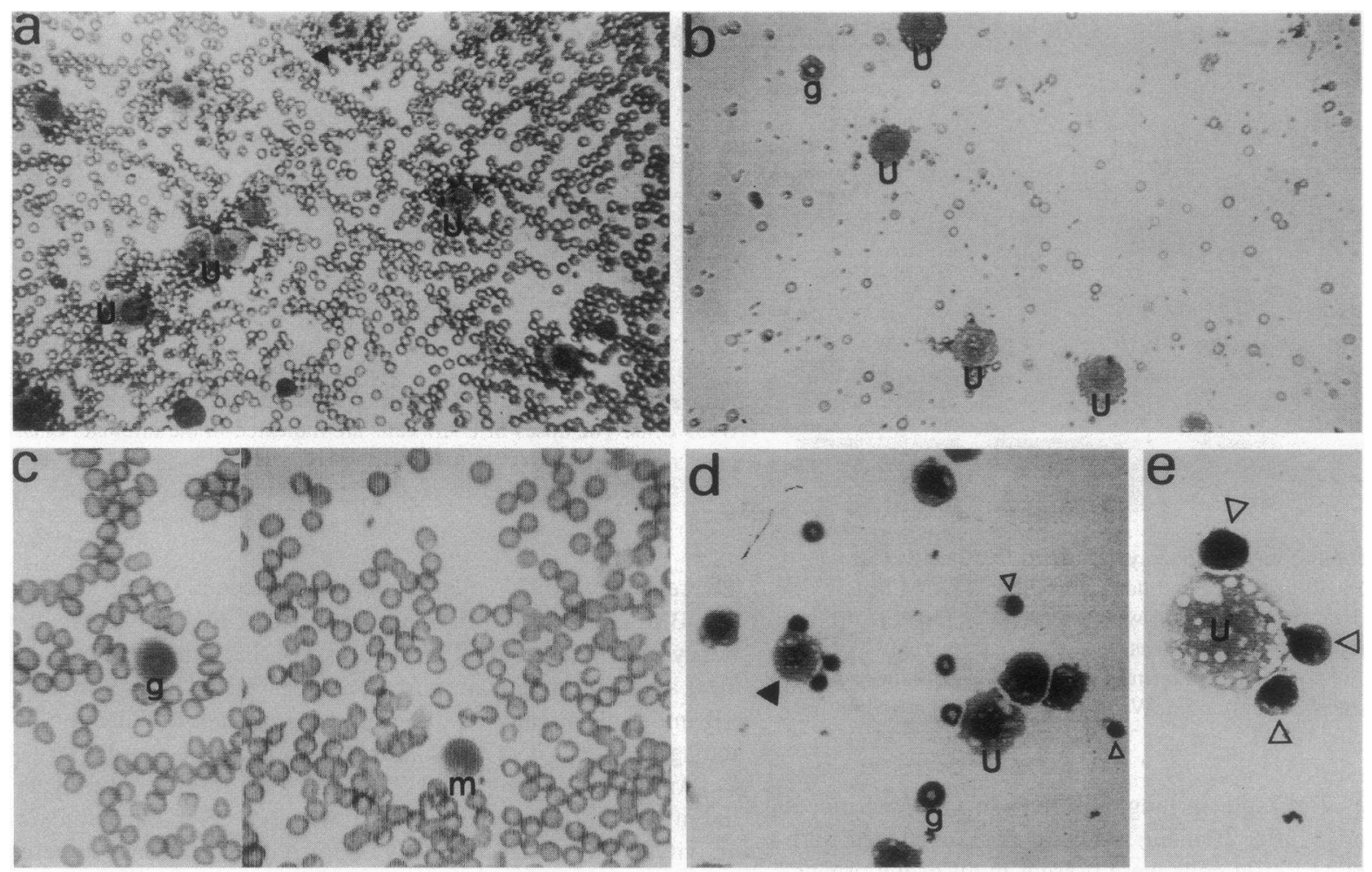

Figure 6. Evaluation of U937 cell infiltration in the PB ( $a$ and $b)$ and BM ( $d$ and $e$ ) of SCID mice sacrificed at different intervals. PB smears and BM cytospins were stained with May-Grünwald Giemsa. $(c)$ The BM of a control mouse containing normal murine hematopoietic elements. $(d)$ The BM from an experimental mouse treated with TALL-104 cells: noteworthy is the presence of a TALL-104/U937 (full arrow) conjugate which, in vitro, precedes the delivery of the lethal hit (18-20). (e) An enlargement of this conjugate. Magnifications were $200 \times(a$ and $b), 400 \times(c$ and $d)$, and $1000 \times(e) . U$, U937 cells; empty arrows, TALL-104 cells; $g$, granulocytes; $m$, monocytes.

mice receiving U937 and TALL-104 cells alone, without rh IL-12.

Overall, the findings in Fig. 7 indicate that, depending on the tumor load at the time of treatment, adoptive transfer of TALL-104 cells either induced complete abrogation of AML or inhibited significantly tumor growth even during advanced stages of the disease. Thus, the extent of tumor reduction appears to reflect the $\mathrm{E} / \mathrm{T}$ ratio at the time of treatment. The

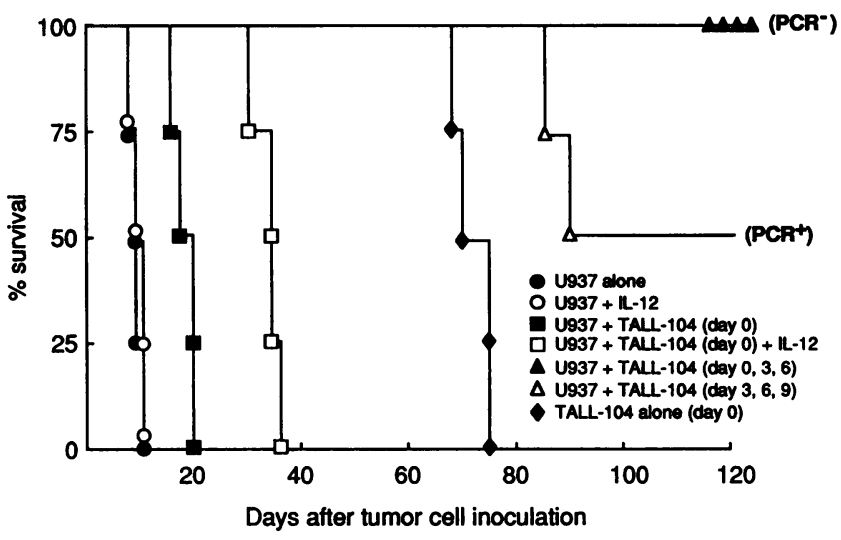

Figure 7. Survival of U937-engrafted SCID mice after treatment with nonirradiated TALL-104 cells. Mice received $10^{7}$ U937 cells i.p. TALL104 cells, activated ex vivo with $100 \mathrm{U} / \mathrm{ml}$ rh IL-2, were injected i.p. $\left(2 \times 10^{7}\right.$ cells $)$ at various intervals, as indicated. rh IL-12 was given to one group of mice i.p. for $7 \mathrm{~d}$ at the dose of $1 \mu \mathrm{g} / \mathrm{d}$. detection of TALL-104/U937 cell conjugates in the BM of treated mice (Fig. 6, $d$ and $e$ ) suggests that the anti-tumor effects in vivo occurred by cytocidal mechanisms similar to those observed in vitro.

Anti-leukemic effects of $\gamma$-irradiated TALL-104 cells in the $S C I D / U 937$ model. Based on the observations that lethally irradiated TALL-104 cells express tumoricidal activity in vitro (Fig. 2) and are able to circulate in SCID mouse tissues (Fig. 4), experiments were performed to determine the extent to which irradiated TALL-104 cells display anti-tumor effects in the SCID/U937 model. To have an objective way for detection of MRD in the treated mice, the U937 clone tagged with the neomycin-resistance gene was used in these experiments. In addition to being killed by TALL-104 cells in vitro to the same extent as the unmodified U937 cell line, the neomycintransfected clone displayed exactly the same tumorigenic properties in SCID mice as the parental cells (data not shown). Moreover, the survival of SCID mice engrafted i.p. with the transfected U937 cells (Fig. 8) was similar to that observed with the unmodified cell line (Fig. 5): animals injected i.p. with $10^{7}$ neomycin-tagged cells died by $\mathrm{d} 12$ and those injected with $3 \times 10^{5}$ cells died by d 56 (Fig. 8). Fig. 9 ( $A$ and $B$ ) show the survival curve and PCR data, respectively, from an experiment in which SCID mice were challenged with transfected U937 cells and treated, or not, with the irradiated TALL-104 cells. The effectors were transferred on alternate days $\left(2 \times 10^{7}\right.$, i.p.), starting from the day of U937 cell challenge: as also indicated in the experiment shown in Fig. 7, TALL-104 cells were co-injected with U937 cells on d 0 in the opposite flank. 


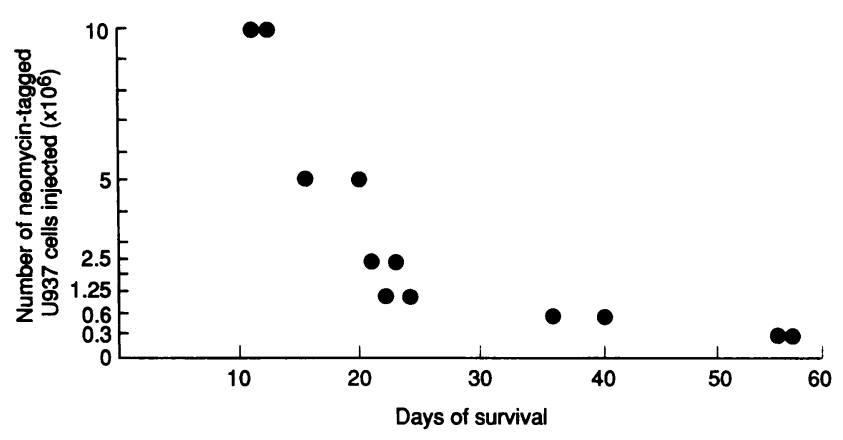

Figure 8. Survival of SCID mice engrafted i.p. with various doses of neomycin-tagged U937 cells. Each point represents an individual mouse.

TALL-104 cells were transferred either alone or in conjunction with rh IL-2 $(100 \mathrm{U} / \mathrm{d})$ or rh IL-12 $(1 \mu \mathrm{g} / \mathrm{d})$, daily for $7 \mathrm{~d}$. All mice receiving only U937 cells $\left(10^{7}\right.$ i.p. $)$, either alone or in combination with daily administration of IL-2 and IL-12 for 1 wk, died between $\mathrm{d} 11$ and 16 (Fig. $9 \mathrm{~A}$ ). In contrast, mice treated with irradiated TALL-104 cells, alone or in conjunction with the cytokines, remained disease-free (looked clinically well and showed no signs of disease) for at least 2 mo (Fig. $9 \mathrm{~A}$ ). At this time, PCR amplification of human ALU-DNA sequences demonstrated the presence of human cells in the BM of mice treated with TALL-104 cells alone or treated with TALL-104 cells and rh IL-12 (Fig. 9 B). PCR analysis using neomycin-specific primers confirmed the presence of residual U937 cells in the same samples (Fig. $9 B$ ). By contrast, administration of rh IL-2 to TALL-104 cell-treated mice resulted in the total disappearance of molecularly detectable leukemic cells, using either type of primers (Fig. $9 \mathrm{~B}$ ). These data indicate that, in vivo, $\gamma$-irradiated TALL-104 cells are still responsive to low doses of rh IL-2, but not of rh IL-12. The cytokine effects on the irradiated cells observed in vivo reflect exactly the in vitro findings that IL-12 is less effective than IL-2 in enhancing the cytotoxicity of irradiated TALL-104 cells (Fig. 3).

\section{Discussion}

The usefulness and potential importance of the SCID mouse as a preclinical model for evaluating the efficacy of adoptive transfer therapy against cancer has been shown in several recent reports. In one study, adoptive transfer of tumor-specific $\mathrm{T}$ cells was shown to induce significant prolongation of survival in SCID mice injected with a B cell lymphoma (29). Takahashi et al. (9) used tumor-targeted LAK cells to inhibit more effectively the growth of human colon cancer in SCID mice. In another study, administration of anti-CD3-activated $T$ cells from healthy donors prolonged the survival of SCID mice engrafted with the HT-29 human colon carcinoma cell line (30). The same investigators also demonstrated the effectiveness against the HT-29 tumor of human T cells co-injected with rh IL7 (31). All together, these data show that, under appropriate conditions, adoptively transferred human lymphocytes can effectively mediate anti-tumor activity in humanized animal models. However, the approaches used by these investigators failed to induce a complete cure in SCID mice. Recent studies by Mazumder's group in immunocompetent mice (32-35) have clearly shown that in a syngeneic BMT setting followed by IL2 therapy, murine BM cells pre-activated with $\mathrm{IL}-2$ in vitro are
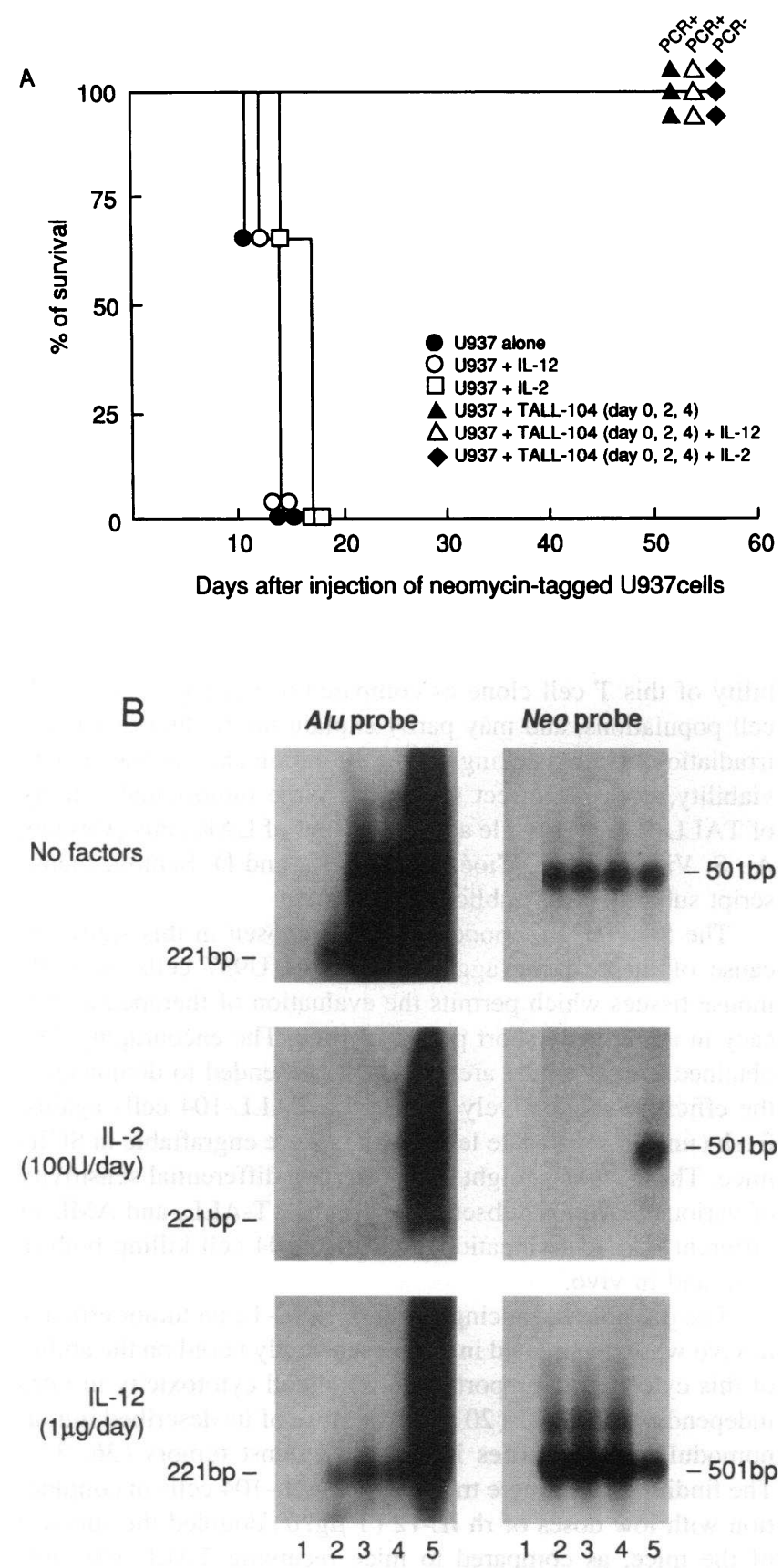

Figure 9. (A) Survival of SCID mice engrafted i.p. with neomycintagged U937 cells and treated with $\gamma$-irradiated TALL-104 cells. Mice received $10^{7}$ U937 cells on d 0, and irradiated TALL-104 cells $\left(2 \times 10^{7}\right)$ three times on alternate days, starting from the day of tumor challenge. Both control (U937 injected) and experimental (U937/TALL-104 injected) mice received IL-2 or IL-12 daily for 1 wk. $(B)$ PCR detection of residual AML in SCID mice upon adoptive transfer of $\gamma$-irradiated TALL-104 cells. Mice received U937 and TALL-104 cells and cytokines, as outlined above (in A). Cellular DNA was extracted on $\mathrm{d} 55$ from the BM of asymptomatic animals and subjected to PCR amplification using primers specific for both human ALU sequences and the neomycin gene. DNAs were visualized with ethidium bromide after electrophoresis in $2 \%$ agarose gels. Southern blots were hybridized with the indicated oligo probes. Lanes 1 and 5 represent the negative (water) and positive (neomycin ${ }^{+}$U937 cells) controls, respectively. Lanes 2-4 represent the experimental mice, which received both U937 and $\gamma$-irradiated TALL-104 cells, in conjunction or not with cytokines. 
able to induce graft-versus-leukemia effects without inducing graft-versus-host disease. Maximum anti-leukemic effects were seen in the early posttransplant period possibly because of MRD during this time (35). These findings might have important clinical implications in future ABMT settings for eradication of MRD by BM-activated killers (34).

The present investigation, performed in humanized SCID mice, demonstrates that a killer $\mathrm{T}$ cell clone, rendered immortal by culture in th IL-2 (17), was able to antagonize efficiently the in vivo growth of the leukemic cell line U937, resulting in complete eradication of AML. TALL-104 cells kill hematopoietic and nonhematopoietic tumors (both cultured and freshly isolated ) 5-20 times more efficiently than IL-2-expanded PBL from healthy donors (conventional LAK cells), yet are unable to recognize and kill cells from normal tissues, such as melanocytes, $\mathrm{PBL}$, and BM cells, both in short-term ${ }^{51} \mathrm{Cr}$-release assays and in long-term (14 d) clonogenic assays (18-20). The extremely low numbers of TALL-104 cells required to kill tumor targets in vitro document the higher potency and recycling capability of this $\mathrm{T}$ cell clone as compared to heterogeneous LAK cell populations, and may partly explain the finding that lethal irradiation, while blocking cell proliferation and decreasing cell viability, does not affect significantly the tumoricidal activity of TALL-104 cells while abolishing that of LAK cells (Cesano, A., S. Visonneau, L. Cioé, S. C. Clark, and D. Santoli, manuscript submitted for publication).

The SCID/U937 model (22) was chosen in this study because of the extreme aggressiveness of U937 cells in SCID mouse tissues which permits the evaluation of therapeutic efficacy in a relatively short period of time. The encouraging data obtained in this model are now being extended to demonstrate the efficacy of adoptively transferred TALL-104 cells against fresh (uncultured) acute leukemias that are engraftable in SCID mice. These studies might demonstrate a differential sensitivity of various leukemia subsets (pre-B ALL, T-ALL, and AML of different FAB classification) to TALL-104 cell killing both in vitro and in vivo.

The possible enhancing effect of rh IL-12 on tumor efficacy in vivo was investigated in the present study based on the ability of this cytokine to support TALL-104 cell cytotoxicity in vitro independently of IL-2 (20), and because of its described immunomodulatory properties in defense against tumors $(36,37)$. The finding that a single transfer of TALL-104 cells in conjunction with low doses of $\mathrm{rh} \mathrm{IL-12}(1 \mu \mathrm{g} / \mathrm{d})$ doubled the survival of the mice, as compared to mice receiving TALL-104 cells alone (Fig. 7), suggests the ability of rh IL-12 to potentiate the tumoricidal activity of this cell line in vivo, in analogy with our in vitro observations (20). To our knowledge, these data provide the first evidence that human $\mathrm{IL}-12$ can enhance the anti-tumor effects of adoptively transferred $\mathrm{CD} 3{ }^{+} \mathrm{CD} 8{ }^{+}$cytotoxic cells in an in vivo situation. On the other hand, the finding that rh IL-12, at the same low dose, did not enhance the antitumor activity of $\gamma$-irradiated TALL-104 cells, as detected both clinically and by PCR (Fig. 9), indicates that, in this situation, the response to IL-12 was inadequate or short lasting, and that higher doses of this cytokine might have to be used to potentiate the killer activity of $\gamma$-irradiated TALL-104 cells in vivo. Indeed, the in vitro findings (Fig. 3 ) that the irradiated killers become totally unresponsive to $\mathrm{rh}$ IL-12 and less responsive to rh IL-2 support the in vivo data in Fig. 9. Experiments are under way to establish the doses of either cytokine that would elicit optimal cytotoxic responses in vitro and highly effective antitumor activity in vivo in the irradiated cells.
Multiple transfers of TALL-104 cells starting at the time of tumor challenge (i.e., when the tumor load was low) resulted in complete abrogation of AML, as seen both clinically and by PCR, regardless of whether adoptive therapy was done with the nonirradiated or the irradiated effectors (Figs. 7 and 9). In the latter case, co-injection of low doses of IL-2 was necessary to obtain total cure. Most notably, when TALL-104 cells were administered $3 \mathrm{~d}$ after tumor challenge (when the leukemic spread of U937 cells was advanced) (Fig. 7), 50\% of the mice showed a significantly longer survival as compared to untreated mice; based on the data in Fig. 5, one can conclude that the tumor load in these animals was significantly reduced upon TALL-104 cell treatment. Remarkably, the remaining 50\% of the mice remained clinically well for at least $6 \mathrm{mo}$. The presence of human ALU-DNA sequences in the BM of these animals at the time they were sacrificed suggests that they harbored residual leukemia. Although we could not rule out the presence of TALL-104 cells in these BM samples, the fact that the group of animals treated at the time of tumor challenge was PCR negative for human ALU-DNA sequences (Fig. 7), suggests that, upon interaction with and killing of the U937 target, the effectors might have become anergic and died. This would be consistent with reported observations on the fate of killer cells after exposure to sensitive targets (28). The anti-leukemic efficacy of $\gamma$-irradiated TALL-104 cells injected during advanced disease has not been investigated in this study. However, in a recently established SCID/U-87MG (human glioblastoma) model, we have found that the anti-tumor efficacy of irradiated TALL-104 cells was high when therapy was started at the time the tumor load was small, and reduced when the effectors were injected into large tumor masses (Cesano, A., S. Visonneau, and D. Santoli, manuscript in preparation). This is a strong indication that lethally irradiated TALL-104 cells would function optimally in a situation mimicking MRD rather than in advanced disease.

In previous reports $(18,20)$, we have provided evidence that TALL-104 cells kill most tumor targets, including U937 cells, via the release of lytic proteins, such as perforin and granzymes, leading to osmotic changes, and necrosis. In some cases (e.g., when Raji cells are used as targets), TALL-104 cells induce primarily nuclear changes followed by apoptotic death (induced suicide or internal disintegration mechanism). Regardless of the mechanism used by TALL-104 cells to deliver the lethal hit, their interaction with the tumor target (binding step) does not appear to require the direct participation of the CD3/TCR complex, because antibodies to CD3 or TCR $\alpha \beta$ do not inhibit TALL-104 cell killing (18). The surface ligands used by these effectors to selectively bind tumor cells are under investigation. Although the data reported here does not prove that TALL-104 cells were the direct effectors of tumor reduction in vivo, several observations suggest that, indeed, the anti-leukemic effects reflect the cytocidal mechanisms of this killer clone. That IL-2 and IL-12 did not trigger natural killer cell activity of the murine host against U937 cells is demonstrated by the fact that animals receiving the cytokines without TALL-104 cells developed leukemia and died at the same time as animals receiving U937 cells alone (Figs. 7 and 9). In consideration that IL-2 and IL-12 induce high levels of IFN- $\gamma$ and TNF- $\alpha$ production by TALL-104 cells (20), we looked at the direct effects of these cytokines on U937 cells in vitro and found that these cells were insensitive to growth inhibition by rh IFN- $\gamma$ and TNF- $\alpha$ at doses as high as $500 \mathrm{U} / \mathrm{ml}$ (data not shown). The inability of neutralizing antibodies to IFN- $\gamma$ and TNF- $\alpha$ to 
affect U937 cell killing by TALL-104 cells in vitro (not shown) is additional evidence against a role of these cytokines in the anti-leukemic effects observed in vivo. That the reversal of AML was a direct result of U937 cell killing by TALL-104 cells is also suggested by the finding that in a group of SCIDU937 mice injected with the noncytotoxic T cell line TALL106 (17), rather than with TALL-104 cells, U937 cell growth was not arrested at all and the animals died of AML at the same time as the control mice (not shown).

Overall, the in vivo experiments shown in this report demonstrate that: $(a)$ nonproliferating TALL-104 cells co-injected with low doses of $\mathrm{IL}-2$ could effectively attack and completely eliminate U937 cells when present at $\mathrm{E} / \mathrm{T}$ ratios $\geq 1: 1$; and $(b)$ even when TALL-104 cell treatment was initiated during an advanced disease stage, at extremely low E/T ratio conditions, TALL-104 cells could still significantly prolong the survival of the mice and drastically reduce the tumor load. These observations point out possible approaches to AML treatment using TALL-104 cells at optimal E/T ratio conditions. Most notably, the observation that, in situations mimicking MRD, $\gamma$-irradiated TALL-104 cells were able to completely eradicate AML indicates the possible clinical efficacy of such cells in leukemic patients in first complete remission, as consolidation therapy. Of course, the biodistribution, half-life, and tumoricidal activity of irradiated TALL-104 cells in multi-transfused, highly sensitized leukemic patients might be different from the situation in SCID mice. Moreover, graft resistance by T cells, macrophages, and NK cells in association with antibodies might result in TALL-104 cell rejection by the patient immune system. Therefore, administration of allogeneic (MHC incompatible) TALL104 cells as consolidation therapy is conceivable only in patients undergoing an immunosuppressive regimen just prior to and during adoptive transfer therapy. To investigate the feasibility of using lethally irradiated TALL-104 cells in MHC incompatible recipients, we have studied the behaviour of this killer clone in immunocompetent mice bearing syngeneic lymphoid leukemia. The data (Cesano, A., S. Visonneau, G. Rovera, and D. Santoli, manuscript in preparation) showed that $100 \%$ of the mice that received multiple transfers of TALL-104 cells on alternate days for $1 \mathrm{wk}$ in conjunction with daily administration of Cyclosporin A (CsA) appeared clinically cured. By contrast, both groups of leukemia-bearing mice treated only with CsA (without TALL104 cells) or only with TALL-104 cells (without CsA), died of leukemia within $12 \mathrm{~d}$. PCR analysis performed 3-mo later on the asymptomatic animals provided molecular evidence for the absence of leukemic cells in their tissues. These preliminary findings suggest that lethally irradiated TALL-104 cells would not be rejected and might be able to function effectively in allogeneic recipients receiving immunosuppressive treatment.

In conclusion, this study indicates that more effective adoptive transfer protocols against cancer can be designed in the future using HLA-mismatched killers co-injected with nontoxic doses of appropriate cytokines and immunosuppressive drugs.

\section{Acknowledgments}

We are indebted to Dr. M. Gately (Hoffman-La Roche, Nutley, NJ) for the generous gift of rh IL-2, and the Genetics Institute Process Development Group for rh IL-12. We also thank Ms. E. Aglow for technical help, Mr. M. Sidelsky for care of the SCID mouse colony, and the Editorial Department of The Wistar Institute for preparing the manuscript.

This work was supported by National Institutes of Health grants
CA-47589, CA-10815, and American Cancer Society grant CH-527. Alessandra Cesano is partially supported by the José Carreras International Leukemia Foundation.

\section{References}

1. Rosenberg, S. A., M. T. Lotze, L. M. Muul, S. Leitman, A. E. Chang, S. E. Ettinghausen, Y. L. Matory, J. M. Skiller, E. Shiloni, J. T. Vetto, C. A. Seipp, C. Simpson, and C. M. Reichert. 1985. Observations on the systemic administration of autologous lymphokine-activated killer cells and recombinant interleukin-2 to patients with metastatic cancer. N. Engl. J. Med. 313:1485-1492.

2. Rosenberg, S. A., M. T. Lotze, L. M. Muul, A. E. Chang, F. P. Avis, S. Leitman, W. M. Linehan, C. N. Robertson, R. E. Lee, J. T. Rubin, C. A. Seipp, C. G. Simpson, and D. E. White. 1987. A progress report on the treatment of 157 patients with advanced cancer using lymphokine-activated killer cells and interleukin-2 or high dose interleukin-2 alone. N. Engl. J. Med. 316:889-897.

3. West, W. H., K. W. Tauer, J. R. Yannelli, G. D. Marshall, D. W. Orr, G. B. Thurman, and R. K. Oldham. 1987. Constant-infusion recombinant interleukin 2 in adoptive immunotherapy of advanced cancer. N. Engl. J. Med. 316:898905.

4. Rosenberg, S. A., M. T. Lotze, J. C. Yang, P. M. Aebersold, W. M. Linehan, C. A. Seipp, and D. E. White. 1989. Experiences with the use of high-dose interleukin-2 in the treatment of 652 cancer patients. Ann. Surg. 210:474-485.

5. Lee, R. E., M. T. Lotze, J. M. Skibber, E. Tucker, R. O. Bonow, F. P. Ognibene, J. A. Carrasquillo, J. H. Shelhamer, J. E. Parrillo, and S. A. Rosenberg. 1989. Cardiorespiratory effects of immunotherapy with interleukin-2. J. Clin. Oncol. 7:7-20.

6. Lotze, M. T., M. C. Custer, E. S. Bolton, E. A. Wiebke, Y. Kawakami, and S. A. Rosenberg. 1990. Mechanisms of immunologic antitumor therapy: lessons from the laboratory and clinical applications. Hum. Immunol. 28:198207.

7. Itoh, K., A. B. Tilden, and C. M. Balch. 1986. Interleukin 2 activation of cytotoxic T-lymphocytes infiltrating into human metastatic melanoma. Cancer Res. 46:3011-3017.

8. Muul, L. M., P. J. Spiess, E. P. Director, and S. A. Rosenberg. 1987. Identification of specific cytolytic immune responses against autologous tumor in humans bearing malignant melanoma. J. Immunol. 138:989-995.

9. Takahashi, H., T. Nakada, and I. Puisieux. 1993. Inhibition of human colon cancer growth by antibody-directed human LAK cells in SCID mice. Science (Wash. DC). 259:1460-1463.

10. Nisticó, P., R. Mortarini, L. B. De Monte, A. Mazzocchi, M. Mariani, F. Malavasi, G. Parmiani, P. G. Natali, and A. Anichini. 1992. Cell retargeting by bispecific monoclonal antibodies. Evidence of bypass of intratumor susceptibility to cell lysis in human melanoma. J. Clin. Invest. 90:1093-1099.

11. Gansbacher, B., K. Zier, B. Daniels, K. Cronin, R. Bannerji, and E. Gilboa. 1990. Interleukin 2 gene transfer into tumor cells abrogates tumorigenicity and induces protective immunity. J. Exp. Med. 172:1217-1224.

12. Gansbacher, B., R. Bannerji, B. Daniels, K. Zier, K. Cronin, and E. Gilboa. 1990. Retroviral vector-mediated $\gamma$-interferon gene transfer into tumor cells generates potent and long lasting antitumor immunity. Cancer Res. 50:7820-7825.

13. Hock, H., M. Dorsch, T. Diamantstein, and T. Blankenstein. 1991. Interleukin 7 induces CD4 ${ }^{+} \mathrm{T}$ cell-dependent tumor rejection. J. Exp. Med. 174:12911298.

14. Golumbeck, P. T., A. J. Lazenby, H. I. Levitsky, L. M. Jaffee, H. Karassuyama, M. Baker, and D. M. Pardoll. 1991. Treatment of established renal cancer by tumor cells engineered to secrete interleukin-4. Science (Wash. DC). 254:713716.

15. Asher, A. L., J. J. Mule, A. Kasid, N. P. Restifo, J. C. Salo, C. M. Reichert, G. Jaffe, B. Fendly, M. Kriegler, and S. A. Rosenberg. 1991. Murine tumor cells transduced with the gene for tumor necrosis factor- $\alpha$. J. Immunol. 146:32273234.

16. Benynes, M. C., J. A. Thompson, A. York, C. D. Buckner, and A. Fefer. 1994. Interleukin $2 \pm$ lymphocytes as consolidative immunotherapy after autologous bone marrow transplantation for hematologic malignancies. In Advances in Bone Marrow Purging and Processing. Wiley-Liss, Inc. In press.

17. O'Connor, R., A. Cesano, B. Lange, J. Finan, P. C. Nowell, S. C. Clark, S. C. Raimondi, G. Rovera, and D. Santoli. 1991. Growth factor requirements of childhood acute $T$ lymphoblastic leukemia: correlation between presence of chromosomal abnormalities and ability to grow permanently in vitro. Blood. 77:1534-1545.

18. Cesano, A., and D. Santoli. 1992. Two unique human leukemic T cell lines endowed with stable cytotoxic function and different spectrum of target reactivity. Analysis and modulation of their lytic mechanisms. In Vitro Cell. Dev. Biol. 28A:648-656.

19. Cesano, A., G. Pierson, and D. Santoli. 1994. An effective and safe marrow purging strategy using a lethally irradiated killer $\mathrm{T}$ cell clone. In Advances in Bone Marrow Purging and Processing. Wiley-Liss, Inc. In press.

20. Cesano, A., S. Visonneau, S. C. Clark, and D. Santoli. 1993. Cellular and molecular mechanisms of activation of MHC non-restricted cytotoxic cells by IL12. J. Immunol. 151:2943-2957. 
21. Cesano, A., R. O'Connor, B. Lange, J. Finan, G. Rovera, and D. Santoli. 1991. Homing and progression of childhood acute lymphoblastic leukemias in severe combined immunodeficiency mice. Blood. 77:2463-2474.

22. Cesano, A., J. A. Hoxie, B. Lange, P. C. Nowell, J. Bishop, and D. Santoli 1992. The SCID mouse as a model for human myeloid leukemias. Oncogene. 7:827-836.

23. Cesano, A., R. O'Connor, P. C. Nowell, B. Lange, S. Clark, and D. Santoli. 1993. Establishment of a karyotypically normal cytotoxic leukemia Tcell line for a T-ALL sample engrafted in SCID mice. Blood. 81:2714-2722.

24. Armentano, D., S. F. Yu, P. W. Kautoff, T. VonRuden, W. F. Anderson, and E. Gilboa. 1987. Effect of internal viral sequence on the utility of retroviral vectors. J. Virol. 61:1647-1650.

25. Gilboa, E., M. A. Eglitis, P. W. Kautoff, and W. F. Anderson. 1986. Transfer and expression of cloned genes using retroviral vectors. Biotechniques. 4:504-512.

26. Felgner, P. L., T. R. Gadek, M. Holm, R. Roman, H. W. Chan, M. Wenz, J. P. Northrop, G. M. Ringold, and M. Danielsen. 1987. Lipofection: a highly efficient, lipid-mediated DNA-transfection procedure. Proc. Natl. Acad. Sci. USA. 84:7413-7417.

27. Nelson, D. L., S. A. Ledbetter, L. Corbo, M. F. Victoria, R. RamirezSolis, T. D. Webster, D. H. Ledbetter, and C. T. Caskey. 1989. Alu polymerase chain reaction: a method for rapid isolation of human-specific sequences from complex DNA sources. Proc. Natl. Acad. Sci. USA. 86:6686-6690.

28. Xiao, J., and Z. Brahmi. 1989. Target cell-directed inactivation and IL-2 dependent reactivation of LAK cells. Cell Immunol. 122:295-306.

29. Malkovska, V., F. K. Cigel, N. Armstrong, B. E. Storer, and R. Hong. 1992. Antilymphoma activity of human $\gamma \delta \mathrm{T}$-cells in mice with severe combined immune deficiency. Cancer Res. 52:5610-5616.

30. Murphy, W. J., K. C. Conlon, T. J. Sayers, R. H. Wiltrout, T. C. Back, J. R. Ortaldo, and D. L. Longo. 1993. Engraftment and activity of anti-CD3- activated human peripheral blood lymphocytes transferred into mice with severe combined immune deficiency. J. Immunol. 150:3634-3642.

31. Murphy, W. J., T. C. Back, K. C. Coulon, K. L. Komschlies, J. R. Ortaldo, T. J. Sayers, R. H. Wiltrout, and D. L. Longo. 1993. Antitumor effects of interleukin-7 and adoptive immunotherapy on human colon carcinoma xenografts. J. Clin. Invest. 92:1918-1924.

32. Charak, B. S., R. Agah, R. K. Brynes, M. Chogyoji, S. Groshen, S. C. Chen, and A. Mazumder. 1992. Interleukin-2 (IL-2) and IL-2-activated bone marrow in transplantation: evaluation from a clinical perspective. Bone Marrow Transplant. 9:479-486.

33. Charak, B. S., G. D. Choudhary, M. Tefft, and A. Mazumder. 1992 Interleukin-2 in bone marrow transplantation: preclinical studies. Bone Marrow Transplant. 10:103-111.

34. Charak, B. S., R. K. Brynes, M. Chogyoji, and A. Mazumder. 1992. Lymphokine-activated killer cells in autologous bone marrow transplantation. Evidence against inhibition of engraftment in vivo. Transplantation. 54:10081013.

35. Charak, B. S., R. K. Brynes, M. Chogyoji, V. Kortes, M. Tefft, and A. Mazumder. 1993. Graft-versus-leukemia effect after transplantation with interleukin-2-activated bone marrow. Correlation with eradication of residual disease. Transplantation. 56:31-37.

36. Kobayashi, M., L. Fitz, M. Ryan, R. M. Hewick, S. C. Clark, S. Chan, R. Loudon, R. Sherman, B. Perussia, and G. Trinchieri. 1989. Identification and purification of natural killer cell stimulatory factor (NKSF), a cytokine with multiple biologic effect on human lymphocytes. J. Exp. Med. 170:827-845.

37. Gately, M. K., B. B. Desai, A. G. Wolitzky, P. M. Quinn, C. M. Dwyer, F. J. Podlaski, P. C. Familletti, F. Sinigaglia, R. Chizzonite, U. Gubler, and A. S. Stern. 1991. Regulation of human lymphocyte proliferation by a heterodimeric cytokine, IL-2 (cytotoxic lymphocyte maturation factor). J. Immunol. $147: 874-882$ 